ISSN 1414-6509

\title{
FATORES DETERMINANTES DO DIFERENCIAL DE CRESCIMENTO NO VALE DO JEQUITINHONHA - MINAS GERAIS: 1991 e 2000
}

\author{
Marcelo Yuto Nogueira Sediyama \\ Mestrado em Controladoria e Contabilidade pela Faculdade de Economia, Administração e Contabilidade -USP \\ Endereço para contato: Rua Maria das Neves de Jesus, 39 - Bairro Fátima - Viçosa - MG \\ CEP: 36.570-000 - E-mail: marceloyuto@yahoo.com.br

\section{Geraldo Edmundo Silva Junior} \\ Professor Associado da Universidade Federal de São Carlos (UFSCar) \\ Endereço para contato: Rod. João Leme dos Santos, Km 110, SP-264. Bairro Itinga - Sorocaba - SP \\ Universidade Federal de São Carlos - Campus de Sorocaba; CCGT - Departamento de Economia. \\ CEP 18052-780 - E-mail: gedmundos@ufscar.br
}

Recebido em 13 de abril de 2016. Aceito em 18 de julho de 2016.

\section{RESUMO}

O presente trabalho evidencia os fatores determinantes do diferencial de crescimento entre as cidades do Vale do Jequitinhonha em Minas Gerais. Para tal, utilizou-se o modelo de Solow-Swan Aumentado em que a inclusão de proxies alternativas para o capital humano explicaria em torno de $60 \%$ das variações na renda. Portanto, os diferenciais nos argumentos básicos da forma funcional adotada explicariam o diferencial na renda e não a velocidade de convergência da renda nas especificações condicional e incondicional da renda.

Palavras-chaves: capital humano; crescimento econômico; desenvolvimento econômico.

Classificação JEL: O15 human resources; O47- Measures of Economic Growth; O49 Other

\begin{abstract}
The present aimed to show the factors that determined differences on growth rates in municipalities of Valley of Jequitinhonha in Minas Gerais State. For that, we used the setup of Augmented SolowSwan growth model which explained $60 \%$ of growth variations including human capital proxies. Therefore, the differentials in the basic arguments to functional form would explain the differences in the income. Also it would not explain the speed of convergence of the income in either specification (unconditional or conditional).
\end{abstract}

Keywords: human capital; economic growth; other (convergence);

JEL Classification: O15 human resources; O47- Measures of Economic Growth; O49 Other 


\section{INTRODUÇÃO}

O estado de Minas Gerais é uma das 27 unidades da República Federativa do Brasil, com 853 municípios e uma população estimada em 19,23 milhões de habitantes (2005) ${ }^{1}$. Tem como estados limítrofes: Bahia (norte e nordeste), Espírito Santo (leste), Rio de Janeiro (sudeste), São Paulo (sul e sudeste), Mato Grosso do Sul (oeste) e Goiás e Distrito Federal (noroeste). Sua linha divisória soma 4.727 km, o Produto Interno Bruto (PIB), em 2004, foi de R\$ 166,5 bilhões, ou US\$ 57 bilhões de dólares (9,4\% do PIB do Brasil).

Seus 853 municípios foram agrupados em dez macroregiões de planejamento, discriminados como Central, Mata, Sul de Minas, Centro-Oeste de Minas, Alto Paranaíba, Triângulo, Noroeste de Minas, Norte de Minas, Jequitinhonha/Mucuri e Rio Doce.

Situando-se ao norte do Estado de Minas Gerais, a macrorregião do Vale do Jequitinhonha é banhada pelo rio Jequitinhonha e seus afluentes. Ocupando uma área de mais de 85 mil km², nela vivem aproximadamente 691.798 mil pessoas (2005), distribuídas em 51 municípios, a saber: Almenara, Angelândia, Araçuaí, Aricanduva, Bandeira, Berilo, Cachoeira do Pajeú, Capelinha, Caraí, Carbonita, Chapada do Norte, Comercinho, Coronel Murta, Couto de Magahães de Minas, Datas, Diamantina, Divisópolis, Felício dos Santos, Felisburgo, Francisco Badaró, Gouveira, Itamarandiba, Itaobim, Itinga, Jacinto, Jenipapo de Minas, Jequitinhonha, Joaíma, Jordânia, José Gonçalves de Minas, Leme do Prado, Mata Verde, Medina, Minas Novas, Minas Novas, Monte Formoso, Novo Cruzeiro, Padre Paraíso, Palmópolis, Pedra Azul, Ponto dos Volantes, Presidente Kubitschek, Rio do Prado, Rubim, Salto da Divisa, Santa Maria do Salto, Santo Antonio do Jacinto, São Gonçalo do Rio Preto, Senador Modestino Gonçalves, Turmalina, Veredinha, Virgem da Lapa,

A região é uma das mais pobres do Brasil e apresenta grandes níveis de desigualdade social e econômica sendo essas reveladas por inúmeros indicadores como a renda, a escolaridade, o acesso aos serviços de saúde, a habitação, o saneamento básico, dentre outros.

Dentre suas características destaca-se que a maior parte do solo é árido sendo castigado regularmente por secas e enchentes, em que $75 \%$ de sua população vive na área rural praticando uma agricultura e pecuária rudimentares e de subsistência. Mesmo assim, as perspectivas de alavancagem são mínimas, pois a região, que outrora era formada por florestas e habitada por tribos indígenas, foi vitimada por extensa e intensa degradação pela atividade predatória de mineração e extração do diamante. Ainda que a produção e exportação de pedras preciosas e semipreciosas e da grande expressão de sua pecuária de corte, em termos locais, é salientado o seu verdadeiro enclave de subdesenvolvimento na região sudeste brasileira, (SOUZA 2003).

O presente trabalho procurou destacar que, apesar da característica intrínseca de baixo padrão de crescimento a região apresenta diferenciais significativos de crescimento entre os seus municípios e, tal característica, seria determinada por diferenças nas variáveis fundamentais que explicariam e motivariam o crescimento econômico.

Objetivou-se com o presente estudo verificar a existência de convergência de renda per capita entre os municípios do Vale do Jequitinhonha e identificar os fatores que

\footnotetext{
${ }^{1}$ IPEADATA
} 
explicariam os diferenciais nos níveis de renda, com destaque para a verificação de se os anos médios de escolaridade seriam a melhor proxy do capital humano.

Especificamente, pretendeu-se: analisar as características econômicas e demográficas do Vale do Jequitinhonha; identificar se a variável anos médios de escolaridade causaria algum impactos sobre a produtividade marginal dos fatores (capital físico e humano); destacar a velocidade de convergência de renda per capita entre os municípios do Vale do Jequitinhonha; e verificar e analisar as implicações e significâncias da velocidade de convergência no modelo adotado.

Para tal, o presente trabalho foi dividido nas seções seguintes: a presente seção de seção de introdução; a segunda seção que tratou do referencial do modelo de crescimento; a terceira, da metodologia; a quarta dos resultados e discussão; e, a seção quinta, que apresentou as considerações conclusivas.

\section{REFERENCIAL TEÓRICO}

Estudos sobre a desigualdade, o crescimento econômico e a convergência de renda entre países e regiões têm recebido ao longo dos anos rigorosos tratamentos empíricos e analíticos.

Especificamente, a teoria do crescimento econômico tem como objetivo explicar os movimentos no produto potencial, no emprego e no capital, bem como explicar a distribuição de renda entre as regiões, entre os fatores de produção e, ainda, os diferentes padrões de crescimento das regiões.

A origem da preocupação com o tema, segundo Harcourt (1972), foi a literatura keynesiana de longo prazo $^{2}$ suscitando questões importantes como a proporção entre os fatores de produção, a relação entre e o estoque de capital e o produto, e os possíveis efeitos das mudanças tecnológias sobre o produto e as respectivas diferenças de crescimento entre países e regiões ${ }^{3}$.

Embora passível a testes empíricos rigorosos, os resultados empíricos obtidos na literatura não corroboraram algumas suposições previstas no modelo, principalmente aquelas que versavam sobre a tendência de convergência das variáveis-chave do modelo, relacionadas aos fatos estilizados de Kaldor $^{4}$, ver Romer (2006), mas principalmente a convergência de renda entre os países e/ou regiões.

\footnotetext{
${ }^{2}$ Logo, a controvérsia foi instaurada na literatura como o principal tópico sobre a teoria keynesiana de longo prazo, antecedendo o desenvolvimento da teoria do crescimento econômico neoclássico. A proposta mais razoável para se avaliar a relação entre o crescimento, o capital e a mudança tecnológica era basea-se em uma função de produção agregativa do tipo Cobb-Douglas. Assim, dentre os principais modelos de crescimento, oriundos do debate sobre o crescimento econômico, destacaram-se os modelos agregativos de Solow, Swan, Harrod e Domar.

${ }^{3}$ No mainstream da literatura de crescimento econômico, o modelo de Solow (1956) é o ponto de partida para a discussão dos possíveis fatores que afetam o crescimento do produto per capita no longo prazo. Solow (1956) apresentou um modelo de crescimento de longo prazo com todas as hipóteses de Harrod-Domar, exceto a hipótese de proporções fixas dos fatores de produção. A estrutura teórica básica criada permitiu testes empíricos sobre as hipóteses do seu modelo o qual tem sobrevivido por mais de meio século.

${ }^{4}$ Segundo Barro e Sala-i-Martin (1994) os fatos estilziados de Kaldor seeriam os seis seguintes: (i) o produto por trabalhador cresceria continuamente, com tendência de declínio da taxa de crescimento da produtividade; (ii) a relação capital/trabalho apresentaria crescimento contínuo; (iii) a taxa de retorno do capital seria estável;
} 
Com o resíduo de Solow, representando a diferença entre as estimativas e as observações, a literatura passou a considerar outros determinantes do crescimento, flexibilizando hipóteses relevantes como os retornos decrescentes ou constantes à escala, proposta esta sugerida por $\operatorname{Romer}^{5}$ (1994). A partir de algumas mudanças na estrutura padrão foi estabelecido um modelo de crescimento neoclássico aumentado, ver Barro e Sala-i-Martin (2004) e Romer (2006), que consideraria retornos crescentes à escala a partir da inclusão do capital humano, pesquisa e desenvolvimento, learning-by-doing, entre outras possibilidades.

Recentemente, Solow (2005) argumentou que dentre os principais desafios da teoria encontrar-se-iam: uma redefinição da substitutibilidade entre o capital e o trabalho; a observação do crescimento como um fenômeno de médio prazo, a evolução da tecnologia, as variações na produtividade dos fatores, o papel das instituições, o tamanho geográfico, a diversidade regional; e, finalmente, o papel da migração interna.

Muitas contribuições empíricas têm sido estabelecidas, ver Aghion e Durlauf (2005) e Snowdon e Vane (2005). Dentre elas, destacam-se as considerações sobre as diferenças nas variáveis relevantes do modelo de crescimento de Solow, simples e aumentado, para a explicação dos diferenciais de crescimento e sobre a convergência de renda.

\subsection{Educação e Crescimento Econômico}

Lucas (1988 apud MAGALHÃES e MIRANDA, 2005) na tentativa de explicar o crescimento de longo prazo, acrescentou o capital humano aos modelos de crescimento. A teoria do capital humano supõe que a decisão do indivíduo em qual atividade alocar seu tempo no período corrente afeta sua produtividade no período futuro. No modelo de Lucas, uma política que conduz ao aumento constante, no tempo em que as pessoas despendem com qualificação, gera aumento permanente no crescimento do produto por trabalhador. Uma conclusão deste modelo é que uma economia com baixos níveis de capital humano e capital físico permanecerá com menor nível de renda per capita que uma economia mais bem dotada.

A educação da força de trabalho constitui o fator determinante da capacidade de assimilação do conhecimento sendo, portanto, responsável pela absorção adequada da tecnologia produzida nos países da fronteira tecnológica, contribuindo, dessa forma para o processo de convergência (SILVA e ALMEIDA, 2000).

Segundo Nakabashi e Figueiredo (2005) existem dois tipos de efeitos do capital humano sobre a renda, sendo eles o efeito direto e o indireto:

(i) Efeitos diretos no capital humano referem-se àqueles que afetam a renda através da melhora na produtividade marginal do trabalho mantendo todos os outros fatores constantes (capital e tecnologia), isto é, da maior habilidade dos trabalhadores na realização de suas respectivas tarefas;

(ii) Os efeitos indiretos do capital humano no nível e crescimento da renda por trabalhador são os efeitos desse sobre o avanço tecnológico. Sendo, importante insumo na

(iv) a relação capital/produto seria estável; (v) as parcelas do capital e do trabalho no produto permaneceria estável; e (vi) observar-se-ia significante variação na taxa de crescimento da produtividade entre os países.

${ }^{5}$ Ver Romer (1994). 
criação de tecnologia, além de ser um elemento essencial no processo de aquisição de tecnologia criada em períodos anteriores.

Desta forma o número de anos de estudo médios da população economicamente ativa estaria intimamente conectado com o acúmulo de capital humano dos países ou regiões. Todavia, Teixeira e Silva (2005), em estudo sobre o impacto da educação sobre o crescimento econômico dos municípios do estado de São Paulo, verificaram que a educação tem efeito mínimo na explicação do crescimento econômico.

Já Souza (1999 apud SOUZA, 2004), mostrou a importância da variável escolaridade na obtenção de PIB's mais elevados para as regiões. Considerando-se que elevados níveis de escolaridade influenciam de forma positiva a dinâmica interna das regiões, sendo mesmo um de seus principais determinantes.

Garcia, Pons e Mussomlini (2005) afirmam que não somente o nível de escolaridade, mas também a qualidade do sistema educacional é considerada importante variável para explicar o impacto do capital humano sobre o crescimento econômico das regiões.

\subsection{Convergência}

Muitos conceitos de convergência têm sido utilizados para explicar se as diferentes economias tenderiam a equalizar seu nível de desenvolvimento econômico. A hipótese de convergência de renda per capita poderia ser sintetizada como tendência de diminuição contínua, ao longo do tempo, das diferenças de renda entre os países ou regiões analisadas.

A convergência seria uma das principais previsões do modelo neoclássico de crescimento desenvolvido por Solow (1956) e Swan (1956). Segundo aqueles autores a produtividade do capital seria maior em economias relativamente menos avançadas, logo a taxa de crescimento seria maior em países com menor estoque de capital o que levaria a progressiva redução no diferencial de crescimento entre países mais e menos avançados.

Segundo Menezes e Azzoni (2000) existem duas definições para a convergência: primeiro, se duas regiões (ou paises) possuirem o mesmo nível de preferências e tecnologia, deveria haver apenas uma renda de estado estacionário6, e, por conseguinte, com o passar do tempo, a renda per capita dessas duas regiões deveriam igualar-se. Denomina-se este tipo de convergência absoluta. A segunda definição de convergência seria dada em termos da taxa de crescimento. Uma vez que, no modelo de Solow, a taxa de crescimento seria determinada pela taxa do progresso tecnológico exógeno e, como este seria um bem público, todas as regiões teriam acesso ao mesmo nível de tecnologia e assim, atingiriam a mesma taxa de crescimento de estado estacionário exógeno. Entretanto, a renda de estado estacionário dependeria das condições iniciais de cada região, de modo que, não necessariamente, tenderiam a se igualar. Esta forma de convergência seria denominada de convergência condicional.

Uma terceira hipótese diz respeito à formação de clubes de convergência que se caracteriza pela persistência de disparidades econômicas, todavia haveriam polarizações e consolidações de grupos de países (ou regiões) com padrões de crescimento similares. De

\footnotetext{
${ }^{6}$ Uma economia se encontra no estado estacionário quando todas as variáveis (estoque de capital, produto, consumo, investimento e poupança) assumirem um valor constante no tempo.
} 
acordo com esta hipótese, as rendas per capita dos países com idênticas características estruturais convergiriam no longo prazo desde que as condições iniciais (nível inicial de renda per capita) também fossem similares.

Todavia, além de todas essas hipóteses listadas, o conceito de convergência- $\sigma$ seria também utilizado para mensurar a dispersão da renda per capita ao longo do tempo entre as economias (CRAVO e SOUKIAZIS 2006). Um grupo de economias estaria convergindo neste sentido se a diferença da renda per capita diminuísse com o passar do tempo. $\mathrm{O}$ coeficiente de variação, dado pela divisão do desvio-padrão pela média da amostra, seria a medida utilizada para testar a hipótese de convergencia- $\sigma$. Este conceito foi introduzido por Barro (1991), para diferenciá-lo da convergência- $\beta$ associada à convergência condicional. Como argumentou Barro, a convergência- $\sigma$ seria necessária, mas não seria uma condição suficiente para a ocorrência de convergência- $\beta$. Ambos os conceitos seriam úteis, dando diferentes informações a respeito do fenômeno da convergência.

Mankiw, Romer e Weil (1992) testaram seu modelo realizando estimações econométricas sobre a convergência de países, concluindo que o modelo de crescimento Solow expandido (adicionando-se ao modelo o capital humano com fator de produção) seria capaz de explicar os diferenciais de renda entre os países. Além disso, ao contrário de modelos de cresciemtno endógeno, haveria uma indicação de que países com a mesma tecnologia, taxa de acumulação e crescimento populacional tendem a ter uma dinâmica de convergência de suas rendas per capita.

Jones (1997) realizou estimações similares com países. A conclusão básica do modelo foi que os países se encontrariam divididos em dois grupos. As economias acima do $50^{\circ}$ percentil tenderiam a alcançar (catch-up) a economia americana na posição de líder e algumas até mesmo a ultrapassá-la. Já as economias abaixo do $50^{\circ}$ percentil permaneceriam próximas dos níveis de renda de 1990. A conclusão básica do trabalho de Jones foi que haveria uma divergência adicional dos mais pobres com os mais ricos e um processo de convergência, entre si, dos países nos percentis superiores de renda per capita.

\section{METODOLOGIA}

Adotou-se como base, para fins do presente estudo, o modelo de Solow-Saw aumentado, além do modelo de convergência incondicional regressão restrita e irrestrita e o modelo de convergência condicional regressão restrita e irrestrita - todos esses três modelos, sem e com anos de escolaridade com proxy para o capital humano.

Para se obter a metodologia adotada foram realizadas especificações algébricas de acordo com cada modelo adotado para dados de painel. Cabe aqui ressaltar, que a escolha do período de análise (1991 e 2000) baseou-se na disponibilidade de informações dado que os censos demográficos foram realizados nestes anos.

\subsection{Descrição do Modelo Teórico de Solow-Swan Simples e Aumentado}

O aspecto chave do modelo de Solow-Swan é a forma neoclássica da função de produção, que assume retornos constantes de escala, retornos decrescentes de cada fator de 
produção e uma elasticidade de substituição positiva. Conforme Romer (2006) o modelo de Solow-Swan seria especificado pela equação (1):

$Y(t)=F(K(t), A(t) L(t))=K^{\alpha}(A L)^{1-\alpha}$

em que:

$\mathrm{Y}(\mathrm{t})=$ produto da economia;

$\mathrm{K}(\mathrm{t})$ = capital físico da economia;

$\mathrm{L}(\mathrm{t})=$ oferta de trabalho igual à população total da economia;

$\mathrm{A}(\mathrm{t})=$ conhecimento ou efetividade do trabalho na economia;

$\alpha=$ parâmetro associado à produtividade do capital; e

$(1-\alpha)=$ parâmetro associado à produtividade das unidades de trabalho efetivos.

A equação (1) seria uma representação do tipo Cobb-Douglas da função de produção que apresentaria retornos constantes à escala, onde o produto $(\mathrm{Y})$ seria função do capital físico (K) e do trabalho (L), sendo $A>0$ o nível tecnológico, e $\alpha$ uma constante, $0<\alpha<1$, que representaria a participação de cada fator no produto.

Uma estrutura do tipo Cobb-Douglas que representa uma função de produção agregada da economia, apresentaria vantagens e desvantagens. Dentre as vantagens destacase a possibilidade de linearização, a partir de transformação logarítmica e a obtenção das elasticidades parciais de produção, representadas pelos coeficientes da regressão estimada. No que concerne às desvantagens, destacam-se: a indispensabilidade de todos os fatores de produção, isto é, caso alguns deles seja zero, o produto total também o seria; a impossibilidade de análise das fases da função de produção, em virtude da linearidade das isóclinas; a invariância da elasticidade da produção em relação aos fatores e às combinações entre eles e, finalmente, isoquantas assintóticas aos eixos.

Entretanto, em função da facilidade de manipulação algébrica e do tratamento econométrico a estrutura do tipo Cobb-Douglas tem sido amplamente utilizada.

Tomando-se as variáveis na forma intensiva para o produto em relação às unidades de trabalho efetivo e para o capital em relação às unidades de trabalho efetivo, a estrutura seria reespecificada como:

$\frac{Y(t)}{A(t) L(t)} \equiv y(t)=F\left(\frac{K(t)}{A(t) L(t)}, 1\right)=\left(\frac{K}{A L}\right)^{\alpha}=k^{\alpha}$

Do ponto de vista dinâmico o comportamento das variáveis capital, trabalho e progresso tecnológico seriam representados por equações diferenciais de primeira ordem:

$$
\begin{aligned}
& \dot{K}(t)=s Y(t)-\delta K(t) \\
& \dot{L}(t)=n L(t) \\
& \dot{A}(t)=g A(t)
\end{aligned}
$$


em que:

$\dot{K}(t)=$ variação do estoque de capital no tempo;

$\dot{L}(t)=$ variação da oferta de trabalho no tempo;

$\dot{A}(t)=$ variação da tecnologia no tempo;

$\mathrm{s}=$ taxa exógena de poupança;

$\mathrm{n}$ = taxa exógena de crescimento da população;

$\mathrm{g}$ = taxa exógena de crescimento da tecnologia;

$\delta=$ taxa exógena de depreciação do capital.

A relação capital por unidade de trabalho efetivo seria representada pela expressão (6) a qual, ao ser derivada em relação ao tempo, resultaria na trajetória do capital por unidade de trabalho efetivo, conforme a equação (7):

$$
\begin{aligned}
& k(t)=\frac{K(t)}{A(t) L(t)} \\
& \dot{k}(t)=s f(k(t))-(n+g+\delta) k(t)
\end{aligned}
$$

A equação (7) evidenciaria a trajetória de crescimento equilibrado quando $\dot{k}=0$, observadasse as condições de Inada7, conforme Barro e Sala-i-Martin (2004).

No modelo de crescimento de Solow-Swan Aumentado, para suscitar retornos crescentes à escala, inclui-se o capital humano, conforme a expressão (8), a saber:

$Y(t)=F(K(t), H(t), A(t) L(t)) \equiv K(t)^{\alpha} H(t)^{\beta}(A(t) L(t))^{1-\alpha-\beta}$

em que:

$\mathrm{H}(\mathrm{t})=$ estoque de capital humano, $0<\beta<1$.

Reescrevendo-se a expressão (8) em unidades de trabalho efetivo, obter-se-ia a equação (9), após alguma manipulação algébrica:

$$
y(t)=f(k, h)=k^{\alpha} h^{\beta}
$$

em que:

$\mathrm{k}=(\mathrm{K} / \mathrm{AL})=$ capital físico por unidades de trabalho efetivo; $\mathrm{e}$

$\mathrm{h}=(\mathrm{H} / \mathrm{AL})=$ capital humano por unidades de trabalho efetivo.

\footnotetext{
${ }^{7}$ Condições de Inada:

$\lim _{k \rightarrow 0^{+}} \frac{\partial F}{\partial K}=\lim _{\hat{l} \rightarrow 0^{+}} \frac{\partial F}{\partial \hat{L}}=\infty$ e $\lim _{k \rightarrow \infty} \frac{\partial F}{\partial K}=\lim _{\hat{l} \rightarrow \infty} \frac{\partial F}{\partial \hat{L}}=0$. Tais considerações implicam em:

$\lim _{k \rightarrow 0^{+}} f^{\prime}(k)=+\infty$ e $\lim _{k \rightarrow \infty} f^{\prime}(k)=0$
} 
Com as especificações do capital humano em unidades de trabalho efetivo e do estoque de capital físico em unidades de trabalho efetivo, a partir de suas derivadas em relação ao tempo, bem como da determinação do estado estacionário para ambas as variáveis ( $\dot{k}=0$ e $\dot{h}=0$ ), o sistema implicaria na especificação de uma equação estrutural básica passível de testes econométricos para dados do tipo cross-section ou dados de painel, conforme a expressão $(10)^{8}$.

$$
\ln \left(\frac{Y}{L}\right)_{i}=a+g t+\frac{\alpha}{1-\alpha-\beta} \ln \left(s_{k}\right)_{i}+\frac{\beta}{1-\alpha-\beta} \ln \left(s_{h}\right)_{i}-\frac{\alpha+\beta}{1-\alpha-\beta} \ln (n+g+\delta)_{i}+\varepsilon_{i}
$$

em que:

a = parâmetro tecnológico da função de produção;

$\mathrm{g}$ = parâmetro da tendência da tecnologia;

sk = poupança destinada ao capital físico exógena;

sh = poupança destinada ao capital humano exógena;

$\mathrm{n}=$ taxa exógena de crescimento da população;

$\mathrm{g}$ = taxa exógena de crescimento da tecnologia; e

$\delta=$ taxa exógena de depreciação do capital.

A equação (10) representa como o produto per capita depende do crescimento populacional e da acumulação de capital físico e humano.

\subsection{Convergência no Modelo}

A convergência do modelo seria baseada em três conceitos: a convergência absoluta, a convergência condicional e o índice meia-vida. $\mathrm{O}$ primeiro conceito se refere à trajetória dinâmica de longo prazo do modelo de Solow-Swan que seria representado pelo logaritmo da diferença entre o produto atual e o produto inicial, como uma função do produto inicial. A estimativa da convergência absoluta seria baseada na verificação do valor do parâmetro $\lambda$ (lâmbda), nas equações 11 e 12 :

$$
\begin{aligned}
& \ln \left(\left(\frac{Y}{L}\right)_{T}-\left(\frac{Y}{L}\right)_{0}\right)=\gamma-\left(1-e^{-\lambda \Delta t}\right) \ln \left(\frac{Y}{L}\right)_{0} \\
& \lambda=-\frac{\ln (\text { parâmetro }+1)}{\Delta t}
\end{aligned}
$$

em que:

$\mathrm{T}=$ período final;

$\mathrm{t}=$ período inicial;

$\Delta \mathrm{t}=\mathrm{T}-\mathrm{t}$ intervalo de anos;

$\lambda=$ velocidade de convergência; $\mathrm{e}$

\footnotetext{
${ }^{8}$ Ver o trabalho de Mankiw, Romer e Weil (1992) como um exemplo de demonstração da especificação econométrica do modelo de Solow.
} 
$\gamma=$ termo constante que representa o estado estacionário de renda per capita comum dependente de fatores como $s, n, g, \delta$ e $\ln \left(\frac{Y}{L}\right)_{0}$;

parâmetro $=$ coeficiente estimado da variável $\left(1-e^{-\lambda \Delta t}\right)$.

No caso da convergência condicional incluir-se-iam as variáveis-chave do modelo e, então, verificar-se-ia a robustez da velocidade de convergência em relação a inclusão e dos valores das variáveis incluídas, conforme pode ser observado na equação (13).

$\ln \left(\left(\frac{Y}{L}\right)_{T}-\left(\frac{Y}{L}\right)_{0}\right)=\gamma_{1}+\left(1-e^{-\lambda \Delta t}\right) \ln \left(\frac{Y}{L}\right)_{0}+\gamma_{2} \ln \left(s_{K}\right)_{T}+\gamma_{3} \ln (n+g+\delta)_{T}+\ldots+\mu$

em que:

$\mathrm{T}=$ período final;

$0=$ período inicial;

$\Delta \mathrm{t}=\mathrm{T}-0$, intervalo de anos;

$\lambda=$ velocidade de convergência; $\mathrm{e}$

$\mu=$ termo de erro.

Finalmente, o índice meia-vida mostra o número de anos até que o produto alcance a metade do seu valor de longo prazo, conforme a equação (14).

$\Delta t=-\frac{\ln \left(\frac{1}{2}\right)}{\lambda}=T-t$

\subsection{Dados e Tratamento}

$\mathrm{Y}=$ produto interno bruto a preços constantes: anos (1991 e 2000), fonte: www.ipeadata.gov.br;

$\mathrm{H}=$ estoque de capital humano9: anos (1991 e 2000), fonte: www.ipeadata.gov.br;

$\mathrm{K}$ = estoque de capital - proxy (capital residencial total): anos (1991 e 2000), fontes: www.ipeadata.gov.br;

Escolaridade $=$ Número médio de anos de estudo - proxy para estoque de capital humano, fonte: Atlas do Desenvolvimento Humano no Brasil.

L = população economicamente ativa: anos (1991 e 2000), fonte: www.ipeadata.gov.br;

sK $=$ parcela da poupança destina à formação de capital físico $=\Delta K / Y:$ anos $(1991$ e 2000), fonte: www.ipeadata.gov.br;

\footnotetext{
9 Valor esperado presente dos rendimentos anuais (descontados a $10 \%$ a.a.) associados à escolaridade e experiência (idade) da população em idade ativa (15 a 65 anos). O estoque de capital humano é calculado pela diferença entre o rendimento obtido no mercado de trabalho e a estimativa daquele obtido por um trabalhador sem escolaridade e experiência. Para se estimar os rendimentos futuros esperados utilizam-se os coeficientes de retorno à educação e à experiência estimados pelos dados do Censo Demográfico para os anos 1991 e 2000 e da PNAD nos demais anos do período 1981-99. Deflacionado pelo IPCA.
} 
$\mathrm{sH}=$ parcela da poupança destinada à formação de capital humano $=\Delta \mathrm{H} / \mathrm{Y}$; anos $(1991 \mathrm{e}$ 2000), fonte www.ipeadata.gov.br;

$\mathrm{n}$ = taxa exógena de crescimento da população;

$\mathrm{g}=$ taxa exógena de crescimento da tecnologia considerada igual a 5\%10; e

$\delta=$ taxa exógena de depreciação do capital, fonte: $10 \%$ conforme Instrução Normativa SRF $\mathrm{n}^{\mathrm{o}}$ 162, ANEXO II, de 31 de dezembro de 1998.

\section{RESULTADOS E DISCUSSÃO}

A Tabela 1 retratou algumas variáveis sócio-econômicas dos municípios do Vale do Jequitinhonha, apresentando para cada variável sua média obtida, mínimo, máximo e desvio padrão (D.P.).

A variável renda per capita ${ }^{11}$ pode-se observar que houve aumento da média de R $\$$ 74,7 em 1991 para $\mathrm{R} \$ 103,7$ em 2000, ou seja, os municípios tiveram em média um aumento de sua renda per capita de $\mathrm{R}$ \$ 29,0. Diamantina continuou sendo a cidade do Vale do Jequitinhonha que com o maior nível de renda per capita e o menor valor passou a ser do município de Comercinho em 2000.

Ao observar-se a variável que representa o percentual da renda proveniente de transferências governamentais ${ }^{12}$, pode-se notar um agravamento nos valores, visto que, a média nos municípios do Vale foi de 10,7\% em 1991, aumentando para 22,2\% em 2000. Tal fato pode indicar que o aumento na renda per capita de $\mathrm{R} \$ 74,7$ em 1991 para $\mathrm{R} \$ 103,7 \mathrm{em}$ 2000 deve-se em grande parte ao auxilio do governo e não ao aumento da qualificação da força de trabalho. No município de Joaíma em 2000 33,5\% da renda das famílias era proveniente de auxílios do governo, já Angelândia apresentou a menor porcentagem 10,5\%.

O percentual de pessoas com mais de $50 \%$ da renda proveniente de transferências governamentais $^{13}$, constatou-se que houve aumento do seu valor médio de 8,34\% em 1991 para 20,5\% em 2000. Pode-se observar também que em 1991 Couto Magalhães de Minas era a cidade do Vale onde a maior parte da população $(13,04 \%)$ tinha mais de $50 \%$ da renda proveniente de transferências governamentais, já no ano de 2000 Joaíma tomou o posto de Couto Magalhães de Minas, pois passou a ter 30,9\% da população com mais de $50 \%$ da renda proveniente de transferências governamentais.

\footnotetext{
${ }^{10}$ Mankiw, Romer e Weil (1992) consideraram uma taxa de 5\% para $\mathrm{g}+\delta$.

11 Refere-se a razão entre o somatório da renda per capita de todos os indivíduos e o número total desses indivíduos; os valores são expressos em reais de $1^{\circ}$ de agosto de 2000.

${ }^{12}$ Equivale à participação percentual das rendas provenientes de transferências governamentais (aposentadorias, pensões e programas oficiais de auxílio, como renda mínima, bolsa-escola e seguro-desemprego, etc) na renda total familiar.

${ }^{13}$ Percentual de pessoas cuja renda familiar per capita provém, em mais de metade de seu valor total, de rendimentos de aposentadoria, pensão e programas oficiais de auxílio. A renda familiar per capita de cada indivíduo é definida como a razão entre a soma da renda de todos os membros de sua família e o número de membros da mesma.
} 
As taxas de homicídios ${ }^{14}$ entre 2002 e 2004 a média foi de 6,3 homicídios por ano, sendo que 18 cidades (Bandeira, Berilo, Chapada do Norte, Coronel Murta, Couto de Magalhães de Minas, Datas, Divisópolis, Jacinto, Joaíma, Jordânia, José Gonçalves de Minas, Mata Verde, Presidente Kubitschek, Santa Maria do Salto, Santo Antônio do Jacinto, São Gonçalo do Rio Preto, Senador Modestino Gonçalves e Veredinha) do Vale do Jequitinhonha não apresentaram nenhum homicídio neste intervalo e a cidade que apresentou maior taxa de homicídio foi a de Felisburgo 37,0 por ano.

Com relação ao percentual de domicílios com água canalizada ${ }^{15}$ e ao percentual de domicílios com energia elétrica ${ }^{16}$, observa-se que houve uma significativa melhora nestes índices. No entanto, no ano de 2000 em média, apenas 56,6\% dos domicílios das cidades do Vale do Jequitinhonha tinham água canalizada e em média $74,8 \%$ destes possuiam energia elétrica.

$\mathrm{O}$ analfabetismo ${ }^{17}$ na região do Vale e muito elevado sendo em média de $39 \%$ da população acima de 25 anos. No ano de 2000 a cidade que apresentou o menor $16,6 \%$ e maior $51,9 \%$ da população analfabeta foram os municípios de Diamantina e Novo Cruzeiro, respectivamente.

Corroborando com o analfabetismo elevado, os municípios do Vale apresentam baixo número médio de anos de estudos ${ }^{18}$. Em 2000 a média foi de 3,0 anos de estudo um aumento de 0,9 anos de estudo se comparado com a média de 1991.

A expectativa de vida ao nascer foi em média de 62,6 anos em 1991 e de 66,0 anos em 2000. O Índice de desenvolvimento humano municipal (IDH-M) ${ }^{19}$, que representa a "qualidade de vida" dos habitantes dos municípios aumentou sua média de 0,555 em 1991 para 0,649 em 2000. Tanto o Índice de Gini ${ }^{20}$ quanto o Índice L de Theil ${ }^{21}$ são indicadores de desigualdade social, comparando o desempenho médio dos dois índices entre o período analisado podemos observar que houve uma piora nos indicadores. A média entre os municípios era de 0,54 para o Índice de Gini em 1991 e aumentou para 0,59 em 2000, já o Índice L de Theil aumentou de 0,51 para 0,57 em 2000. 14 Evolução dos homicídios na população total - Médias trienais 2002/04. fonte:
http://www.oei.org.br/mapadaviolencia/.

${ }^{15}$ Percentual de pessoas que vivem em domicílios com água canalizada para um ou mais cômodos, proveniente de rede geral, de poço, de nascente ou de reservatório abastecido por água das chuvas ou carro-pipa.

${ }^{16}$ Percentual de pessoas que vivem em domicílios com iluminação elétrica, proveniente ou não de uma rede geral, com ou sem medidor.

${ }_{17}^{17}$ Percentual de pessoas que não sabem ler nem escrever um bilhete simples.

${ }^{18}$ Razão entre o somatório do número de anos de estudo completos das pessoas sobre o total dessas pessoas.

${ }^{19}$ É obtido pela média aritmética simples de três sub-índices, referentes às dimensões Longevidade (IDHLongevidade), Educação (IDH-Educação) e Renda (IDH-Renda).

${ }^{20}$ Mede o grau de desigualdade existente na distribuição de indivíduos segundo a renda domiciliar per capita. Seu valor varia de 0 , quando não há desigualdade (a renda de todos os indivíduos tem o mesmo valor), a 1 , quando a desigualdade é máxima (apenas um indivíduo detém toda a renda da sociedade e a renda de todos os outros indivíduos é nula).

${ }^{21}$ Mede a desigualdade na distribuição de indivíduos segundo a renda domiciliar per capita. É o logaritmo da razão entre as médias aritmética e geométrica das rendas individuais, sendo nulo quando não existir desigualdade de renda entre os indivíduos e tendente ao infinito quando a desigualdade tender ao máximo. Para seu cálculo, excluem-se do universo os indivíduos com renda domiciliar per capta nula. 
A comparação do crescimento do produto per capita entre os anos de 1991 e 2000 foi realizada com base nos resultados obtidos através da utilização das equações estrutural irrestrita e estrutural restrita sem e com escolaridade como proxy para capital humano, na comparação das convergências incondicional e condicional irrestrita e restrita sem e com a proxy escolaridade, observando-se, a velocidade de convergência e o índice de meia-vida.

\subsection{Equações Estruturais Irrestrita e Restrita}

$\mathrm{Na}$ Tabela 2, onde se ilustraram os resultados do crescimento do produto per capita no Modelo de Solow-Swan Aumentado (equação 10), observou-se, para a equação estrutural irrestrita no ano de 1991, que apenas o capital humano $(\ln (\mathrm{sH})$ ) explicou o crescimento do produto per capita. Entretanto, o seu parâmetro foi negativo. 
Tabela 1 Algumas variáveis sócio-econômicas dos municípios do Vale do Jequinhonha.

\begin{tabular}{|c|c|c|c|c|c|c|c|c|}
\hline \multicolumn{9}{|c|}{ Descrição Sócio-Econômica dos municípios do Vale do Jequitinhonha } \\
\hline \multirow{2}{*}{ Variáveis } & \multicolumn{4}{|c|}{ Situação dos municípios em (1991) } & \multicolumn{4}{|c|}{ Situação dos municípios em (2000) } \\
\hline & Média & Minimo & Máximo & D. P. & Média & Minimo & Máximo & D. P. \\
\hline Renda per capita ( $\mathrm{R} \$$ de 2000$)$ & 74,7 & 43,9 & 136,9 & 21,3 & 103,7 & 61,5 & 213,0 & 27,3 \\
\hline Cidade & & Monte Formoso & Diamantina & & & Comercinho & Diamantina & \\
\hline $\begin{array}{c}\text { Percentual da renda proveniente de transferências } \\
\text { governamentais }\end{array}$ & 10,7 & 6,8 & 16,0 & 2,2 & 22,2 & 10,5 & 33,5 & 4,5 \\
\hline Cidade & & Monte Formoso & $\begin{array}{c}\text { Couto de Magalhães de } \\
\text { Minas }\end{array}$ & & & Angelândia & Joaíma & \\
\hline $\begin{array}{l}\text { Percentual de pessoas com mais de } 50 \% \text { da renda provenientes } \\
\text { de transferências governamentais }\end{array}$ & 8,34 & 4,26 & 13,04 & 2,16 & 20,5 & 7,8 & 30,9 & 4,6 \\
\hline Cidade & & Capelinha & $\begin{array}{c}\text { Couto de Magalhães de } \\
\text { Minas }\end{array}$ & & & Angelândia & Joaíma & \\
\hline Crescimento populacional 1991-2000 em \% & * & * & * & * & $-0,70$ & $-7,95$ & 0,82 & 1,69 \\
\hline Cidade & & & & & & Rio do Prado & Carbonita & \\
\hline Taxa de homicídio (2002/2004) & * & * & * & * & 6,3 & 0,0 & 37,0 & 7,5 \\
\hline Cidade & & & & & & (18 cidades) & Felisburgo & \\
\hline Percentual de domicílios com água canalizada & 35,4 & 12,1 & 80,6 & 16,7 & 56,6 & 31,0 & 90,6 & 15,2 \\
\hline Cidade & & Aricanduva & $\begin{array}{c}\text { Couto de } \begin{array}{c}\text { Magalhães de } \\
\text { Minas }\end{array} \\
\end{array}$ & & & Jenipapo de Minas & $\begin{array}{l}\text { Couto de } \begin{array}{c}\text { Magalhães de } \\
\text { Minas }\end{array} \\
\text {. }\end{array}$ & \\
\hline Percentual de domicílios com energia elétrica & 47,5 & 18,6 & 84,5 & 17,9 & 74,8 & 36,4 & 95,7 & 14,3 \\
\hline Cidade & & Monte Formoso & Gouvêa & & & Monte Formoso & $\begin{array}{c}\text { Couto de } \begin{array}{c}\text { Magalhães de } \\
\text { Minas }\end{array} \\
\end{array}$ & \\
\hline Percentual de pessoas com 25 anos ou mais analfabetas & 51,9 & 17,8 & 70,5 & 10,8 & 39,0 & 16,6 & 51,9 & 8,7 \\
\hline Cidade & & Gouvêa & Mata Verde & & & Diamantina & Novo Cruzeiro & \\
\hline $\mathrm{N}^{\circ}$ médio de anos de estudo & 2,1 & 1,1 & 4,4 & 0,7 & 3,0 & 2,1 & 5,7 & 0,7 \\
\hline Cidade & & Monte Formoso & Diamantina & & & Monte Formoso & Diamantina & \\
\hline Esperança de vida & 62,6 & 56,3 & 66,9 & 2,7 & 66,0 & 59,4 & 70,9 & 2,7 \\
\hline Cidade & & $\begin{array}{l}\text { São Gonçalo do Rio } \\
\text { Preto }\end{array}$ & Chapada do Norte & & & $\begin{array}{c}\text { São Gonçalo do Ric } \\
\text { Preto }\end{array}$ & Turmalina & \\
\hline IDH-M & 0,555 & 0,464 & 0,674 & 0,044 & 0,649 & 0,570 & 0,748 & 0,035 \\
\hline Cidade & & Monte Formoso & Diamantina & & & Monte Formoso & Diamantina & \\
\hline Índice de Gini & 0,54 & 0,45 & 0,70 & 0,06 & 0,59 & 0,46 & 0,69 & 0,05 \\
\hline Cidade & & Chapada do Norte & Joaíma & & & Chapada do Norte & Joaíma & \\
\hline Índice $L$ de Theil & 0,51 & 0,34 & 0,90 & 0,12 & 0,57 & 0,33 & 0,85 & 0,11 \\
\hline Cidade & & Chapada do Norte & Joaíma & & & Chapada do Norte & Joaíma & \\
\hline
\end{tabular}


No ano de 2000 os resultados foram expressivos para a constante que representa a tecnologia e a tendência da sua taxa exógena de crescimento. Os parâmetros relacionados tanto ao capital humano quanto ao capital físico apresentaram significância estatística, explicando o que ocorre na realidade. Entretanto tiveram sinal negativo, contrário ao esperado pela teoria. Indicando que os municípios do Vale do Jequitinhonha apresentam uma variação negativa do capital humano e do capital físico no tempo. Todavia, as equações estruturais restritas mostraram que para o ano de 1991 o parâmetro relacionado ao capital humano menos o parâmetro relacionado à combinação crescimento da população, crescimento da tecnologia e depreciação $\ln (n+g+\delta)$ e o parâmetro relacionado ao capital físico menos o parâmetro relacionado à combinação crescimento da população, crescimento da tecnologia e depreciação foram significativos.

Os testes de restrição evidenciaram que tanto o parâmetro da produtividade do capital físico e da produtividade do capital humano foi negativo. Conseqüentemente, o crescimento do produto per capita seria explicado, em grande parte, pelo coeficiente das unidades de trabalho efetivo (1- $\alpha-\beta)$ que apresentou sinal positivo. Em relação ao ano de 2000 para a equação estrutural restrita, os resultados evidenciaram-se semelhantes aos do ano de 1991. O teste de restrição paramétrica (teste de Wald) mostrou que somente o parâmetros das unidades de trabalho efetivo $(1-\alpha-\beta)$ apresentaram produtividade marginal crescente, enquanto o parâmetro vinculado ao capital físico $\alpha$ e capital humano $\beta$ seriam negativos e portanto, contrário ao esperado pela teoria.

Tabela 2 Modelo de Solow-Swan Aumentado

\begin{tabular}{|c|c|c|c|c|}
\hline $\begin{array}{l}\text { Var. Dependente: } \\
\ln (Y(t) / L(t))\end{array}$ & $\begin{array}{c}\text { Equação } \\
\text { Estrutural } \\
\text { irrestrita }\end{array}$ & $\begin{array}{c}\text { Equação estrutural } \\
\text { restrita }\end{array}$ & $\begin{array}{c}\text { Equação estrutural } \\
\text { irrestrita }\end{array}$ & $\begin{array}{c}\text { Equação estrutural } \\
\text { restrita }\end{array}$ \\
\hline Período & 1991 & 1991 & 2000 & 2000 \\
\hline Constante & $\begin{array}{l}1,320^{\mathrm{NS}} \\
(0,323)\end{array}$ & $\begin{array}{c}0,855^{\mathrm{NS}} \\
(0,164)\end{array}$ & $\begin{array}{c}2,275 \\
(0,000)\end{array}$ & $\begin{array}{l}1,670^{*} \\
(0,001)\end{array}$ \\
\hline $\ln (\mathrm{sK})$ & $\begin{array}{c}-0,309 \\
(0,000)\end{array}$ & - na - & $\begin{array}{c}-0,286 \\
(0,000)\end{array}$ & - na - \\
\hline $\ln (\mathrm{sH})$ & $\begin{array}{c}-0,060^{\mathrm{NS}} \\
(0,106)\end{array}$ & - na - & $\begin{array}{c}-0,061 * \\
(0,045)\end{array}$ & - na - \\
\hline $\ln (n+g+\delta)$ & $\begin{array}{c}0,192^{\mathrm{NS}} \\
(0,663)\end{array}$ & - na - & $\begin{array}{c}-0,010 \mathrm{NS} \\
(0,946)\end{array}$ & - na - \\
\hline $\ln (\mathrm{sK})-\ln (\mathrm{n}+\mathrm{g}+\delta)$ & - na - & $\begin{array}{l}-0,303 \\
(0,000)\end{array}$ & - na - & $\begin{array}{l}-0,258 \\
(0,000)\end{array}$ \\
\hline $\ln (\mathrm{sH})-\ln (\mathrm{n}+\mathrm{g}+\delta)$ & - na - & $\begin{array}{c}-0,061 * * \\
(0,094)\end{array}$ & - na - & $\begin{array}{c}-0,053 * * \\
(0,087)\end{array}$ \\
\hline $\mathrm{R}^{2}$ corrigido & 0,5814 & 0,5910 & 0,6544 & 0,6227 \\
\hline Prof. > F & 0,0000 & 0,0000 & 0,0000 & 0,0000 \\
\hline S. Q. Res. & 1,0377 & 1,0423 & 0,7263 & 0,8151 \\
\hline $\mathrm{n}^{\mathrm{o}}$ obs. & 40 & 40 & 40 & 40 \\
\hline Teste de Restrição & - na - & $\begin{array}{c}731.00 \\
(0,0000)\end{array}$ & - na - & $\begin{array}{l}1106.42 \\
(0,0000)\end{array}$ \\
\hline Valor de $\alpha$ & - na - & $-0,4764$ & - na - & $-0,3744$ \\
\hline Valor de $\beta$ & - na - & $-0,0959$ & - na - & $-0,0769$ \\
\hline Valor de $(1-\alpha-$ & - na - & 1,5723 & - na- & 1,4513 \\
\hline
\end{tabular}

Fonte: Resultados obtidos pelos autores com o uso do Software Stata v.9.2

( ) erro padrão de estimativa; NS - não significativo; na - não se aplica, * 5\% de significância; ** 10\% de significância. e $\delta=10 \%$. 
A Tabela 3 apresenta os resultados do Modelo de Solow-Swan Aumentado com anos de escolaridade como proxy para capital humano. Onde pode-se observar que a principal diferença ao se utilizar a proxy foi que ela passou a apresentar valores positivos, ou seja, aumento nos anos médios de estudo explicariam aumentos na renda per capita dos municípios em aproximadamente 59\% para o ano de 1991 e de 64\% para o ano de 2000 nas equações estruturais restritas.

Tabela 3 Modelo de Solow-Swan Aumentado com escolaridade

\begin{tabular}{|c|c|c|c|c|}
\hline $\begin{array}{l}\text { Var. Dependente: } \\
\ln (Y(t) / L(t))\end{array}$ & $\begin{array}{c}\text { Equação estrutural } \\
\text { irrestrita }\end{array}$ & $\begin{array}{c}\text { Equação } \\
\text { estrutural } \\
\text { restrita }\end{array}$ & $\begin{array}{c}\text { Equação } \\
\text { estrutural } \\
\text { irrestrita }\end{array}$ & $\begin{array}{c}\text { Equação } \\
\text { estrutural } \\
\text { restrita }\end{array}$ \\
\hline Período & 1991 & 1991 & 2000 & 2000 \\
\hline Constante & $\begin{array}{l}3,711^{*} \\
(0,009)\end{array}$ & $\begin{array}{c}2,898 \\
(0,000)\end{array}$ & $\begin{array}{c}3,039 \\
(0,000)\end{array}$ & $\begin{array}{c}3,020 \\
(0,000)\end{array}$ \\
\hline $\ln (\mathrm{sK})$ & $\begin{array}{l}-0,248 \\
(0,000)\end{array}$ & - na - & $\begin{array}{l}-0,250 \\
(0,000)\end{array}$ & - na - \\
\hline $\ln (\mathrm{esc})$ & $0,289 * *$ & - na - & $0,2611^{\mathrm{NS}}$ & - na - \\
\hline $\ln (n+g+\delta)$ & $\begin{array}{c}-0,349^{\mathrm{NS}} \\
(0,468)\end{array}$ & - na - & $\begin{array}{c}-0,036^{\mathrm{NS}} \\
(0,824)\end{array}$ & - na - \\
\hline $\ln (\mathrm{sK})-\ln (\mathrm{n}+\mathrm{g}+\delta)$ & - na - & $\begin{array}{c}-0,241 \\
(0,000)\end{array}$ & - na - & $\begin{array}{l}-0,246 \\
(0,000)\end{array}$ \\
\hline $\ln (\mathrm{esc})-\ln (\mathrm{n}+\mathrm{g}+\delta)$ & - na - & $\begin{array}{c}0,282 * * \\
(0,054)\end{array}$ & - na - & $\begin{array}{l}0,273^{*} \\
(0,019)\end{array}$ \\
\hline R2 corrigido & 0,5954 & 0,6009 & 0.6391 & 0,6487 \\
\hline Prof. $>\mathrm{F}$ & 0,0000 & 0,0000 & 0,0000 & 0,0000 \\
\hline S. Q. Res. & 1,0032 & 1,0170 & 0,7586 & 0,7588 \\
\hline $\mathrm{n}^{\mathrm{o}}$ obs. & 40 & 40 & 40 & 40 \\
\hline Teste de Restrição & - na - & $\begin{array}{c}26.53 \\
(0,0000)\end{array}$ & - na - & $\begin{array}{c}56.11 \\
(0,0000)\end{array}$ \\
\hline Valor de $\alpha$ & - na - & $-0,2663$ & - na - & $-0,2772$ \\
\hline Valor de $\beta$ & - na - & 0,1614 & - na - & 0,1531 \\
\hline Valor de $(1-\alpha-\beta)$ & - na - & 1,1049 & - na - & 1,1241 \\
\hline
\end{tabular}

Fonte: Resultados obtidos pelos autores com o uso do Software Stata v.9.2

( ) erro padrão de estimativa; NS - não significativo; na - não se aplica, * 5\% de significância; ** 10\% de significância. e $\delta=10 \%$.

Comparando-se os resultados das Tabelas 2 e 3 observou-se que a inclusão da proxy melhorou os resultados dos parâmetros tanto para o ano de 1991 como para o ano de 2000 na equação estrutural restrita. A melhora na confiabilidade dos resultados para a equação estrutural restrita pode ser atestada pela melhora no ajustamento do modelo, que apresentou leve aumento nos valores dos $\mathrm{R}^{2}$ obtidos.

Todavia a produtividade do capital físico continuou sendo negativa, contrariando o esperado pela teoria, entretanto a produtividade dos anos de estudo foi positiva e as unidades de trabalho efetivo apresentariam melhor retorno no modelo anterior com capital humano.

As Figuras 1-4 apresentam a distribuição das variáveis anos de escolaridade e capital

humano nos anos de 1991 e 2000 para os municípios do Vale do Jequitinhonha. As representações gráficas abaixo têm por objetivo melhorar a forma de visualização das variáveis e suas distribuições nos municípios ao longo do período analisado. 


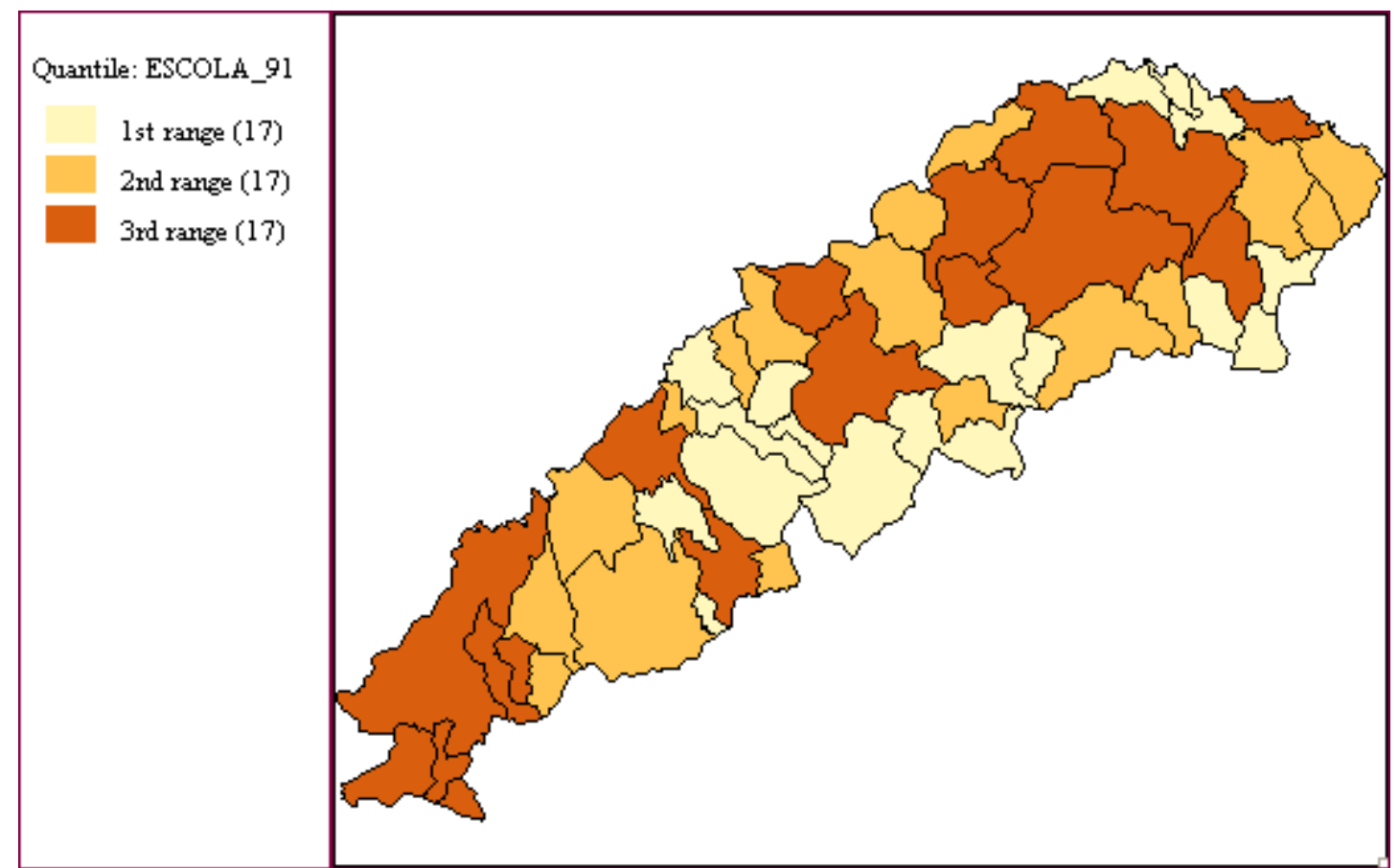

Figura 1: Distribuição da variável anos médios de escolaridade em 1991 entre os municípios do Vale do Jequitinhonha em 3 ranges ou percentis.

Fonte: Resultados obtidos pelos autores com o uso do Software GeoDa 0.9.5-i (Beta).

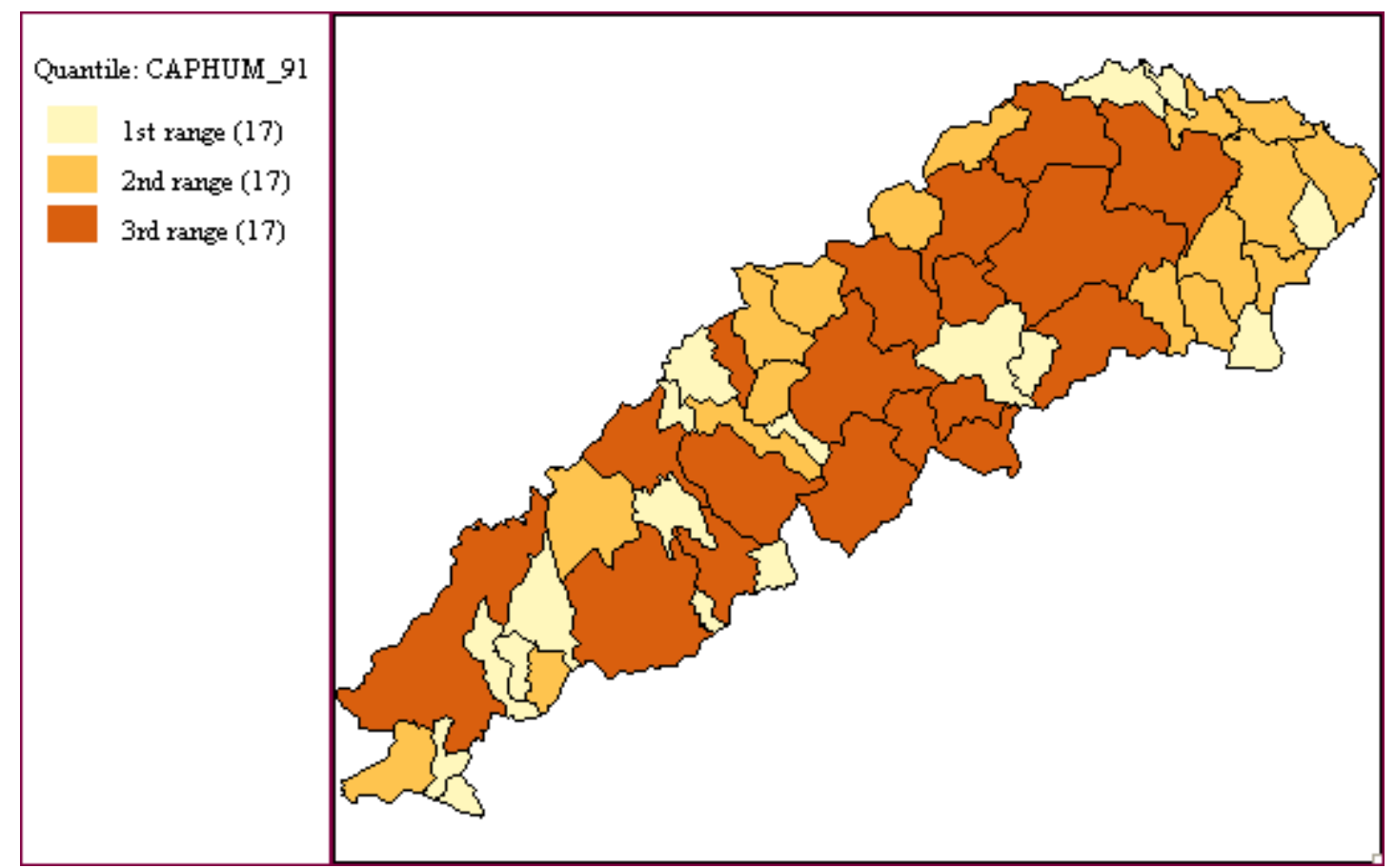

Figura 2: Distribuição da variável Capital Humano em 1991 entre os municípios do Vale do Jequitinhonha em 3 ranges ou percentis.

Fonte: Resultados obtidos pelos autores com o uso do Software GeoDa 0.9.5-i (Beta). 


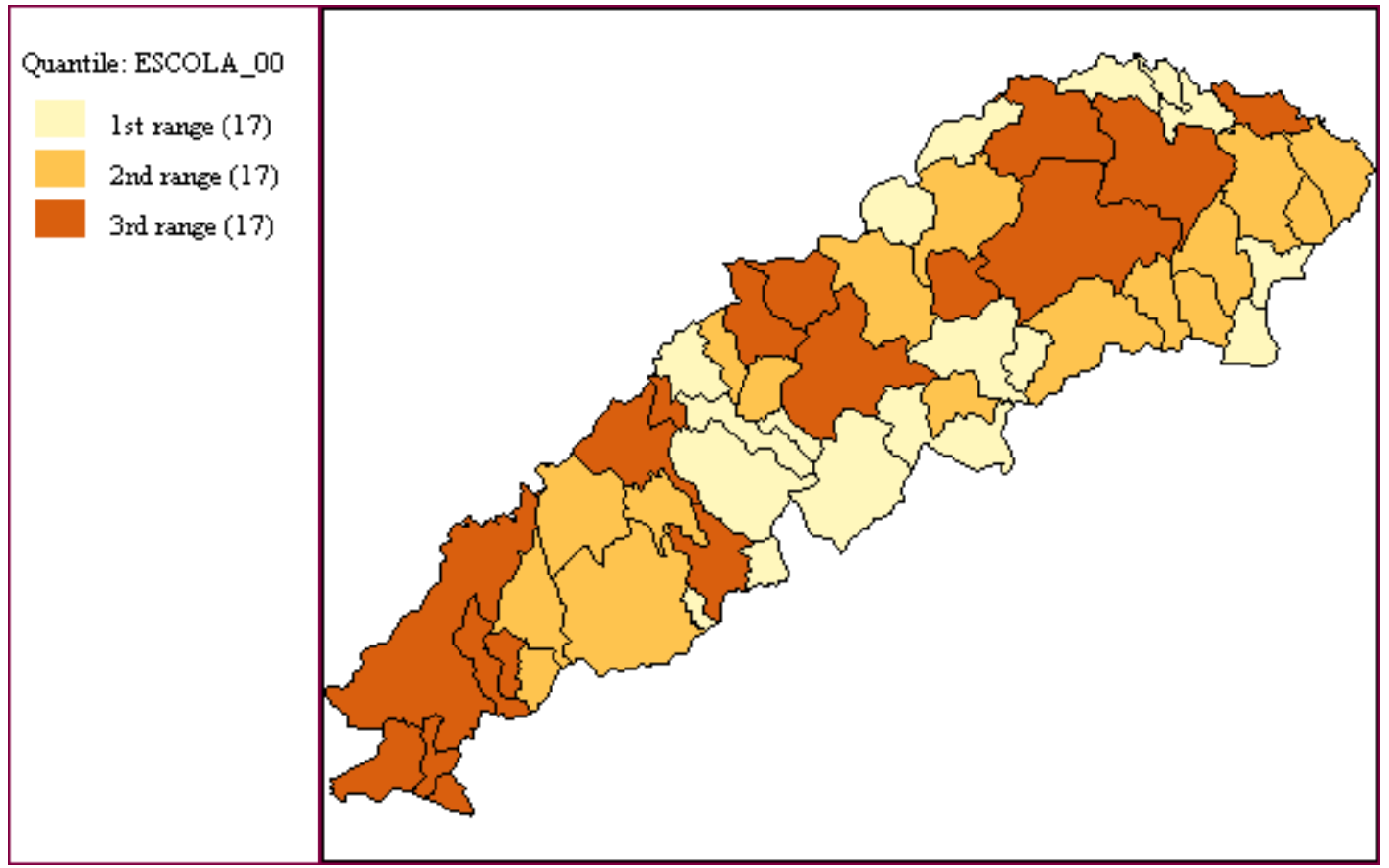

Figura 3: Distribuição da variável anos médios de escolaridade em 2000 entre os municípios do Vale do Jequitinhonha em 3 ranges ou percentis.

Fonte: Resultados obtidos pelos autores com o uso do Software GeoDa 0.9.5-i (Beta).

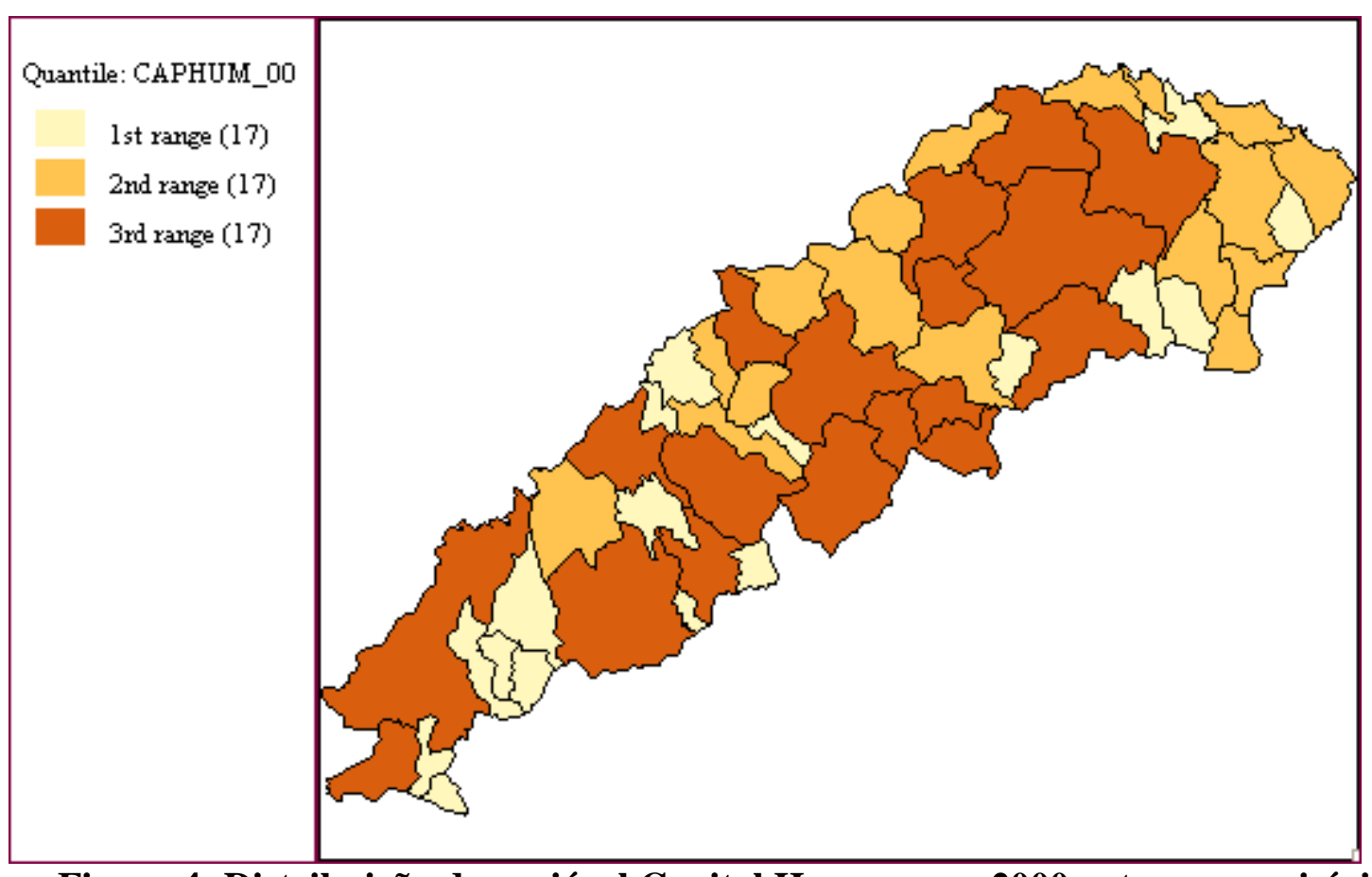

Figura 4: Distribuição da variável Capital Humano em 2000 entre os municípios do Vale do Jequitinhonha em 3 ranges ou percentis.

Fonte: Resultados obtidos pelos autores com o uso do Software GeoDa 0.9.5-i (Beta). 


\subsection{Convergências Incondicional e Condicional e Regressões Irrestrita e Restrita}

No modelo de convergência incondicional observou-se que os parâmetros foram significativos (Tabela 4) e a velocidade de convergência foi de aproximadamente 3,17\% e intervalo superior a vinte anos para que a metade do estado estacionário fosse alcançada por todos os municípios do Vale do Jequitinhonha.

Para a convergência condicional regressão irrestrita a velocidade de convergência foi de 8,32\% entre o período de 1991-2000. Com este resultados os índices meia-vida (equação 14) foi de 8,33 anos para que os municípios do Vale venham a alcançar metade do caminho para convergir seus níveis de renda per capita.

Pelo resultado obtido na convergência condicional regressão restrita pode-se constatar que o $\mathrm{R}^{2}$ obtido foi praticamente duas vezes maior ao $\mathrm{R} 2$ da Convergência incondicional, todavia ainda e muito baixo, cerca de 31,9\%. Após os testes de restrição dos parâmetros (teste de Wald) observou-se que os parâmetros relacionados à produtividade do capital físico e humano foram negativos e contrários ao esperado pela teoria. O índice meia-vida foi de 9,14 anos.

\section{Tabela 4 Convergência Incondicional e Condicional, Regressões Restrita e Irrestrita}

\begin{tabular}{|c|c|c|c|}
\hline $\begin{array}{l}\text { Var. Dependente: } \\
\ln (Y(t) / L(t))-\ln (Y(t-1) / L(t-1)\end{array}$ & $\begin{array}{l}\text { Convergência } \\
\text { Incondicional }\end{array}$ & $\begin{array}{c}\text { Convergência } \\
\text { Condicional } \\
\text { Regressão Irrestrita }\end{array}$ & $\begin{array}{c}\text { Convergência } \\
\text { Condicional } \\
\text { Regressão Restrita }\end{array}$ \\
\hline Período & $2000 / 1991$ & $2000 / 1991$ & $2000 / 1991$ \\
\hline Constante & $\begin{array}{c}1,395 \\
(0,000)\end{array}$ & $\begin{array}{l}1,364^{*} \\
(0,008)\end{array}$ & $\begin{array}{l}0,884^{*} \\
(0,039)\end{array}$ \\
\hline $\ln (\mathrm{Y}(\mathrm{t}-1) / \mathrm{L}(\mathrm{y}-1))$ & $\begin{array}{c}-0,2481^{*} \\
(0,001)\end{array}$ & $\begin{array}{c}-0,5272 \\
(0,000)\end{array}$ & $\begin{array}{r}-0,4947 \\
(0,000)\end{array}$ \\
\hline $\ln (\mathrm{sK})$ & - na - & $\begin{array}{l}-0,148^{*} \\
(0,002)\end{array}$ & - na - \\
\hline $\ln (\mathrm{sH})$ & - na - & $\begin{array}{c}-0,043^{* *} \\
(0,081)\end{array}$ & - na - \\
\hline $\ln (n+g+\delta)$ & - na - & $\begin{array}{c}-0,063^{\mathrm{NS}} \\
(0,630)\end{array}$ & - na - \\
\hline $\ln (\mathrm{sK})-\ln (\mathrm{n}+\mathrm{g}+\delta)$ & - na - & - na - & $\begin{array}{c}-0,119^{*} \\
(0,009)\end{array}$ \\
\hline $\ln (\mathrm{sH})-\ln (\mathrm{n}+\mathrm{g}+\delta)$ & - na - & - na - & $\begin{array}{c}-0,037^{\mathrm{NS}} \\
(0,141)\end{array}$ \\
\hline R2 corrigido & 0,1718 & 0,3593 & 0,3192 \\
\hline Prof. > F & 0,0015 & 0,0005 & 0,0007 \\
\hline S. Q. Res. & 0,9768 & 0,4681 & 0,5117 \\
\hline$\Lambda$ & 0,0317 & 0,0832 & 0,0758 \\
\hline $\mathrm{n}^{\mathrm{o}}$ obs. & 51 & 40 & 40 \\
\hline Teste de Restrição & - na - & - na - & $\begin{array}{c}623.79 \\
(0,0000)\end{array}$ \\
\hline Valor de $\alpha$ & - na - & - na - & $-0,1913$ \\
\hline Valor de $\beta$ & - na - & - na - & $-0,0730$ \\
\hline Valor de $(1-\alpha-\beta)$ & - na - & - na - & 1,2644 \\
\hline Meia-Vida & 21,88 & 8,33 & 9,14 \\
\hline
\end{tabular}

Fonte: Resultados obtidos pelos autores com o uso do Software Stata v.9.2

( ) erro padrão de estimativa; NS - não significativo; na - não se aplica, * 5\% de significância; ** $10 \%$ de significância. e $\delta=10 \%$. 
Com a inclusão da proxy para o capital humano, verificou-se que a convergência condicional irrestrita não apresentou resultados significativos, uma vez que a própria proxy foi não significativa, apesar de ter apresentado valor negativo e condizente com o esperado pela teoria. O teste de restrição dos parâmetros revelou uma produtividade marginal do capital físico negativa e produtividade da proxy e das unidades de trabalho efetivo positivas, ou seja, aumento da média dos anos de estudo aumenta a produtividade marginal da força de trabalho.

\section{Tabela 5 Convergência Incondicional e Condicional, Regressões Restrita e Irrestrita} (escolaridade)

\begin{tabular}{|c|c|c|c|}
\hline $\begin{array}{l}\text { Var. Dependente: } \\
\ln (Y(t) / L(t))-\ln (Y(t-1) / L(t-1)\end{array}$ & $\begin{array}{l}\text { Convergência } \\
\text { Incondicional }\end{array}$ & $\begin{array}{c}\text { Convergência } \\
\text { Condicional } \\
\text { Regressão Irrestrita }\end{array}$ & $\begin{array}{c}\text { Convergência } \\
\text { Condicional } \\
\text { Regressão Restrita }\end{array}$ \\
\hline Período & 2000/1991 & $2000 / 1991$ & $2000 / 1991$ \\
\hline Constante & $\begin{array}{c}1,395 \\
(0,000)\end{array}$ & $\begin{array}{c}1.880 \\
(0,000)\end{array}$ & $\begin{array}{c}1.863 \\
(0,000)\end{array}$ \\
\hline $\ln (\mathrm{Y}(\mathrm{t}-1) / \mathrm{L}(\mathrm{y}-1))$ & $\begin{array}{c}-0,2481 * \\
(0,001)\end{array}$ & $\begin{array}{c}-0,5159 \\
(0,000)\end{array}$ & $\begin{array}{c}-0,5158 \\
(0,000)\end{array}$ \\
\hline $\ln (\mathrm{sK})$ & - na - & $\begin{array}{c}-0,120 \\
(0,026)\end{array}$ & - na - \\
\hline $\ln (\mathrm{esc})$ & - na - & $\begin{array}{c}0,180^{\mathrm{NS}} \\
(0,182)\end{array}$ & - na - \\
\hline $\ln (\mathrm{n}+\mathrm{g}+\delta)$ & - na - & $\begin{array}{c}-0,081^{\mathrm{NS}} \\
(0,542)\end{array}$ & - na - \\
\hline $\ln (\mathrm{sK})-\ln (\mathrm{n}+\mathrm{g}+\delta)$ & - na - & - na - & $\begin{array}{c}-0,117 * \\
(0,008)\end{array}$ \\
\hline $\ln (\mathrm{esc})-\ln (\mathrm{n}+\mathrm{g}+\delta)$ & - na - & - na - & $0,190^{*}$ \\
\hline $\mathrm{R}^{2}$ corrigido & 0,1718 & 0,3353 & 0,3536 \\
\hline Prof. > F & 0,0015 & 0,0010 & 0,0003 \\
\hline S. Q. Res. & 0,9768 & 0,4857 & 0,4858 \\
\hline$\lambda$ & 0,0317 & 0,0806 & 0,0806 \\
\hline$n^{\circ}$ obs. & 51 & 40 & 40 \\
\hline Teste de Restrição & - na - & - na - & $\begin{array}{c}76.49 \\
(0,0000)\end{array}$ \\
\hline Valor de $\alpha$ & - na - & - na - & $-0,0971$ \\
\hline Valor de $\beta$ & - na - & - na - & 0,1036 \\
\hline Valor de $(1-\alpha-\beta)$ & - na - & - na - & 0,9935 \\
\hline Meia-Vida & 21,88 & 8,60 & 8,60 \\
\hline
\end{tabular}

Fonte: Resultados obtidos pelos autores com o uso do Software Stata v.9.2

( ) erro padrão de estimativa; NS - não significativo; na - não se aplica, * 5\% de significância; ** $10 \%$ de significância. e $\delta=10 \%$.

Comparando-se os resultados dos testes de convergência condicional regressão restrita sem e com a proxy para capital humano no período analisado de 2000/1991, constatou-se que a utilização da proxy acelera a velocidade de convergência de renda per capita entre os municípios do Vale do Jequitinhonha, diminuindo assim, o índice meia-vida, ou seja, a metade do tempo para que eles alcancem o estado estacionário. 


\section{CONSIDERAÇÕES CONCLUSIVAS}

Conforme metodologia do modelo de Solow-Swan Aumentado foram calculadas duas equações uma com capital humano e outra com escolaridade. Para verificar a convergência de renda foram feitos testes de convergência incondicional e condicional com regressões restritas e irrestritas.

Os resultados revelam que as equações poderiam explicar mudanças na velocidade de convergência da renda per capita ou do índice meia-vida nos municípios do Vale do Jequitinhonha, apesar dos modelos de convergência apresentaram baixa explicação paramétrica.

Constatou-se também que tanto capital humano quanto a escolaridade apresentaram praticamente os mesmos resultados, explicando aproximadamente $60 \%$ das variações na renda para os modelos de Solow-Swan aumentado. Logo projetos de desenvolvimento regional que aumentem a formação de capital humano ou o tempo médio de escolaridade teriam o mesmo impacto sobre o crescimento da renda per capita na região.

Os resultados obtidos para os modelos de Convergência Condicional, Regressão Restrita e Irrestrita indicam que a educação tem efeito mínimo na explicação do crescimento econômico, visto que os coeficientes são na maioria de baixa magnitude, e que o poder de explicação da variável dependente pelas exógenas é baixo não ultrapassando $36 \%$, indicando que especificações alternativas poderiam ser mais adequadas.

Este resultado corrobora com os de DIAS et al (2005) onde afirma que, os resultados contraditórios entre o crescimento econômico e a educação se devem pela errada especificação da relação entre essas duas variáveis. De acordo com o autor a relação entre as duas variáveis é não linear na forma de U invertido. Por esse motivo os trabalhos que encontraram um resultado positivo provavelmente estariam utilizando uma amostra em que o predomínio seria a primeira fase do $U$ invertido. Os demais trabalhos em que se tem uma maior amostra não encontrariam qualquer relação entre essas duas variáveis, já que os pontos de influência positiva seriam cancelados pelos de influência negativa.

Por fim, tal estudo revela que as disparidade regionais de renda nos municípios do Vale do Jequitinhonha dificilmente serão reduzidas pelo simples aumento nos anos médios de estudo dos habitantes. A oferta da educação é condição necessária, mas não suficiente para se elevar significativamente a renda, a produtividade marginal do capital e do trabalho das pessoas nestes municípios. 


\section{REFERÊNCIAS BIBLIOGRÁFICAS}

AGHION, P.; DURLAUF, S., Handbook of Economic Growth, volume 1A. Amsterdam: Elsevier North Holland, 2005

BARRO, R., Economic Growth in a Cross-section of Countries, Quarterly Journal of Economics, v. 106, n.2, p. 407-443, 1991

BARRO, R.; MANKIW, N.; SALA-I-MARTIN, X.; Capital mobility in neoclassical models of growth, American Economic Review , v. 85, n. 1, p.103-115, 1995

BARRO, R.; SALA-I-MARTIN, X.; Economic Growth, Cambridge: The MIT Press, 2004

CRAVO, T.; SOUKIAIS, E.; Human capital as a conditioning factor to the convergence process among the Brazilian States". CEUNEUROP Working Paper, n 35, 2006

DIAS, J.; DIAS, M.; LIMA, F.; Crescimento Econômico e Nível de Escolaridade: Teoria e Estimativas Dinâmicas em Painel de Dados", .. Anais.... VIII Encontro de Economia da Região Sul - ANPEC SUL, 2005

GARCIA, F.; PONS, T.; MUSSOLINI, C.; "Os Efeitos da qualidade do ensino sobre o crescimento econômico", Anais .... XXXIII Encontro Nacional de Economia da ANPEC, Natal-RN, ANPEC, 2005

HARCOURT, G.; Some Controversies in Theory of Capital, Cambridge: Cambridge University Press, 1972

JONES, C.; Convergence Revisited, Journal of Economic Growth, v.2, p.131-153, 1997

MAGALHÃES, J.; MIRANDA, R; "Dinâmica da renda, longevidade e educação nos municípios brasileiros", Anais... XXXIII Encontro Nacional de Economia da ANPEC, NatalRN, 2005.

MANKIW, N.; ROMER, D.; WEIL, D.; A Contribution to the Empirics of Economic Growth, Quarterly Journal of Economics, v.107, n.2, p.407-437, 1992

MENEZES, T.; AZZONI, C.; "Convergência de renda real e nominal entre as regiões metropolitanas brasileiras: uma análise de dados de painel”. Anais... XXVIII Encontro Nacional de Economia, 2000, Campinas-SP, 2000

NAKABASHI, L. FIGUEIREDO, L.; Capital Humano e crescimento: impactos diretos e indiretos, Texto para Discussão n ${ }^{\circ}$ 267, CEDEPLAR/Universidade Federal de minas Gerais, 35p., 2005.

ROMER, D.; Advanced Macroeconomics, New York: McGraw-Hill Irwin, 2006

ROMER, P.; The origins of endogenous growth, Journal of Economic Perspectives, v.8, n.1, p.3-22, 1994 
SILVA, A.; ALMEIDA, M.; "Educação e o Processo de Convergência: Um Teste Empírico Para a Indústria de Transformação Brasileira". Estudos Econômicos № 20, CAENUniversidade Federal do Ceará, 26p. 2000

SNOWDON, B.; VANE, H.; Modern Macroeconomics: Its Origins, Development and Current State, Cheltenahm, UK: Edward Elgar, 2005

SOLOW, R.; A Contribution to the Theory of Economic Growth, Quarterly Journal of Economics, v.70, n.1, p.65-94, 1956

SOLOW, R.; Reflections on Growth Theory, In: P. AGHION, S. DURLAUF (ed.'s), Handbook of Economic Growth, volume 1A, Amsterdam: Elsevier North Holland, p.3-10, 2005

SOUZA, J.; "Fontes para uma reflexão sobre a história do Vale do Jequitinhonha". UNIMONTES CINETÍFICA, p.1-21, v.5, n.2, 2003.

SOUZA, M.; Fatores determinantes do crescimento das regiões: um processo de mensuração. Florianópolis: Tese de Doutorado, Universidade Fedeal de Santa Catarina, Programa de Pós-Graduação em Engenharia de Produção e Sistemas, 2004

SWAN, T.; Economic growth and capital accumulation, Economic Record, v.32, p.334-361, 1956

TEIXEIRA, E.; SILVA, R.; Educação e crescimento econômico: uma análise econométrica para os municípios de São Paulo (1980-2000) URL [On line]: http://www.mackenzie.com.br/jovenspesquisadores/3.4/3.4.08.pdf. Acesso em 10 abril de 2007 